\title{
Tract integrity in amyotrophic lateral sclerosis: 6-month evaluation using MR diffusion tensor imaging
}

\author{
Ashwag R. Alruwaili ${ }^{1}$, Kerstin Pannek ${ }^{2}$, Robert D. Henderson ${ }^{3}$, Marcus Gray ${ }^{4}$, Nyoman D. Kurniawan ${ }^{4}$ and \\ Pamela A. McCombe $5^{5^{*}}$
}

\begin{abstract}
Background: This study was performed to assess changes in diffusion tensor imaging (DTI) over time in patients with amyotrophic lateral sclerosis (ALS).

Methods: We performed DTI in 23 ALS patients who had two magnetic resonance imaging (MRI) scans at 6 month intervals and to correlate results with clinical features. The revised ALS functional rating scale (ALSFRS-R) was administered at each clinical visit. Data analysis included voxel-based white matter tract-based spatial statistics (TBSS) and atlas-based region-of-interest (ROI) analysis of fractional anisotropy (FA) and mean diffusivity (MD).

Results: With TBSS, there were no significant changes between the two scans. The average change in FA and MD in the ROls over 6 months was small and not significant after allowing for multiple comparisons. After allowing for multiple comparisons, there was no significant correlation of FA or MD with ALSFRS-R.
\end{abstract}

Conclusion: This study shows that there is little evidence of progressive changes in DTI over time in ALS. This could be because white matter is already substantially damaged by the time of onset of symptoms of ALS.

Keywords: Amyotrophic lateral sclerosis, Motor neuron disease, Diffusion tensor imaging, Voxel based morphometry, Tract-based spatial statistics, Cognitive impairment

\section{Background}

Amyotrophic lateral sclerosis (ALS) is a neurodegenerative disease defined by loss of upper and lower motor neurons. However, extra-motor dysfunction can also be found in ALS [1] with cognitive impairment being prominent [2]. Magnetic resonance imaging (MRI) studies of ALS have reported pathological changes in white matter (WM), using diffusion tensor imaging (DTI), and in gray matter (GM) [3, 4]. There are changes in major white matter tracts in ALS [5], and changes in gray and white matter are more severe in patients with cognitive impairment [6].

For clinical monitoring and for use in clinical trials there is a need for a biomarker that is related to disease

\footnotetext{
* Correspondence: Pamela.McCombe@uq.edu.au

${ }^{5}$ Faculty of Medicine, UQ Centre for Clinical Research, Royal Brisbane and Women's Hospital, The University of Queensland, Herston, QLD 4029,

Australia

Full list of author information is available at the end of the article
}

pathology [7]. Imaging biomarkers have the advantage of being non-invasive. DTI provides a measure of white matter changes. In ALS, cross-sectional studies have focused on abnormalities in the corticospinal tract (CST) [8-10], where it is widely accepted that there is reduction in fractional anisotropy (FA), although some studies have reported the involvement of association tracts and subcortical structures $[11,12]$. Changes in mean diffusivity (MD) are less frequently studied, although in our previous study we found that MD shows changes in ALS [6]. It might be expected that serial DTI studies could be useful as a measure of the rate of progression of disease and could also demonstrate the spread of pathology to different regions [13].

There have been some longitudinal studies of DTI in ALS [14-17]. These have given inconsistent findings. Using a region of interest approach, some have reported the progression of ALS by demonstrating decreasing FA over time along the CST $[14,15]$, while another found

(C) The Author(s). 2019 Open Access This article is distributed under the terms of the Creative Commons Attribution 4.0 International License (http://creativecommons.org/licenses/by/4.0/), which permits unrestricted use, distribution, and 
that FA does not change on later scans [16]. There have been some recent studies suggesting changes in axial diffusivity (AD) in the spinal cord over time [18] and radial diffusivity (RD) over time [19]. A study using ${ }^{1} \mathrm{H}$ magnetic resonance spectroscopy gave negative findings [17]. To obtain further value from MRI biomarkers, there is also a need for correlation of MRI findings with clinical status.

This study explores the changes in WM of motor and extra-motor pathways over time using tract-based spatial statistics (TBSS) and region-of-interest (ROI) analysis in 23 patients who had two MRI scans, 6 months apart, analyzing FA and MD. The primary hypothesis was that the later scan would show greater WM damage than the first scan and the secondary hypothesis was that changes in WM would correlate with changes in disease severity.

\section{Methods}

Participants

Patients with ALS were recruited from the multidisciplinary Motor Neuron Disease clinic at the Royal Brisbane Women Hospital (RBWH). All patients fulfilled the criteria for definite ALS according to revised El Escorial criteria [20]. The patients were classified into the phenotypes described by Chio et al. [21]. All participants in the present study were participants in a previous cross-sectional MRI study of 30 subjects with ALS [6]. The revised ALS functional rating scale (ALSFRS-R) was administered at each clinical visit [22]. All ALS subjects also received cognitive and behavioral testing, using the Addenbrooke's cognitive examination III (ACE-III) [23, 24] and the Frontal Assessment battery (FAB) [25] on the day of the first MRI scan. The study was approved by the RBWH Human Research Ethics Committee (HREC 2008/98) and all patients provided written informed consent. All activities were conducted in accordance with relevant guidelines.

\section{Image acquisition}

MRI scans were performed at RBWH using a $3 \mathrm{~T}$ Siemens Tim Trio (Siemens, Erlangen, Germany) equipped with a 12-channel parallel head coil. In addition to a standard series of clinical sequences, diffusion-weighted images (DWIs) were acquired along 64 non-collinear directions at $b=3000 \mathrm{~s} / \mathrm{mm}^{2}$, with one non-diffusion weighted image. Acquisition parameters were: 60 axial slices, FOV $30 \times 30 \mathrm{~cm}$, slice thickness $2.5 \mathrm{~mm}$, matrix $128 \times 128$, TR/TE $9200 / 112 \mathrm{~ms}$, iPAT factor 2 . A field map was acquired using two $2 \mathrm{D}$ gradient-recalled echo images with TE1/TE2 $=4.76 / 7.22 \mathrm{msec}$ to assist in the correction of geometric distortions. The acquisition time for the diffusion dataset was 9:40 min.

\section{Diffusion processing}

Diffusion MRI data were preprocessed as described previously [26]. Preprocessing methods included correction for head movement with rotation of the b-matrix, detection and removal of signal intensity outliers, and correction for geometric distortions and intensity inhomogeneity. Maps of FA and MD were calculated using MRtrix 0.2.9.

A custom FA template, generated using the scripts provided with the Advanced Normalization Tools Software (ANTS) package (http://picsl.upenn.edu/ANTS/) [27], was derived from all subjects. We used ANTS symmetric diffeomeophic registrations using symmetric image normalization (Greedy SyN). The Johns Hopkins University (JHU) $1 \mathrm{~mm}$ FA was used for the initial rigid body registration to generate the template. The JHU atlas [28] was normalized to this study template using symmetric diffeomorphic registration. JHU atlas ROIs were subsequently transformed to the individual datasets in native space by applying the inverse transform.

\section{Tract-based spatial statistics (TBSS)}

Tract-based spatial statistics analysis was performed with the Functional MRI of the Brain (FMRIB) Software Library (FSL) package version 5.0 (www.fmrib.ox.ac.uk/fsl/tbss) [29] which is a fully automated whole brain analysis technique that uses voxel-wise statistics on DTI data while simultaneously minimizing the effects of misalignment [29]. Briefly, the main steps were a) non-linear alignment of FA images to 1x1x1 mm MNI152 standard space, b) creation of the

Table 1 List of regions-of-interest investigated in this study ROls

Corticospinal tract

Corona radiata (CR) (right and left)

Medial lemniscus (ML) (right and left)

Pons (midline)

Posterior internal capsule (PLIC) (right and left)

Callosal tracts

Forceps minor FMi) (right and left)

Genu corpus callosum (gCC) (midline)

Body corpus callosum (bCC) (midline)

Splenium corpus callosum (sCC) (midline)

Association fibers

Superior longitudinal fasciculus (SLF) (right and left)

Inferior longitudinal fasciculus (ILF) (right and left)

Other extramotor tracts

Cinglum (Cg) (midline)

Hippocampus (Hpc) (right and left)

Anterior limb of internal capsule (ALIC) (right and left) 

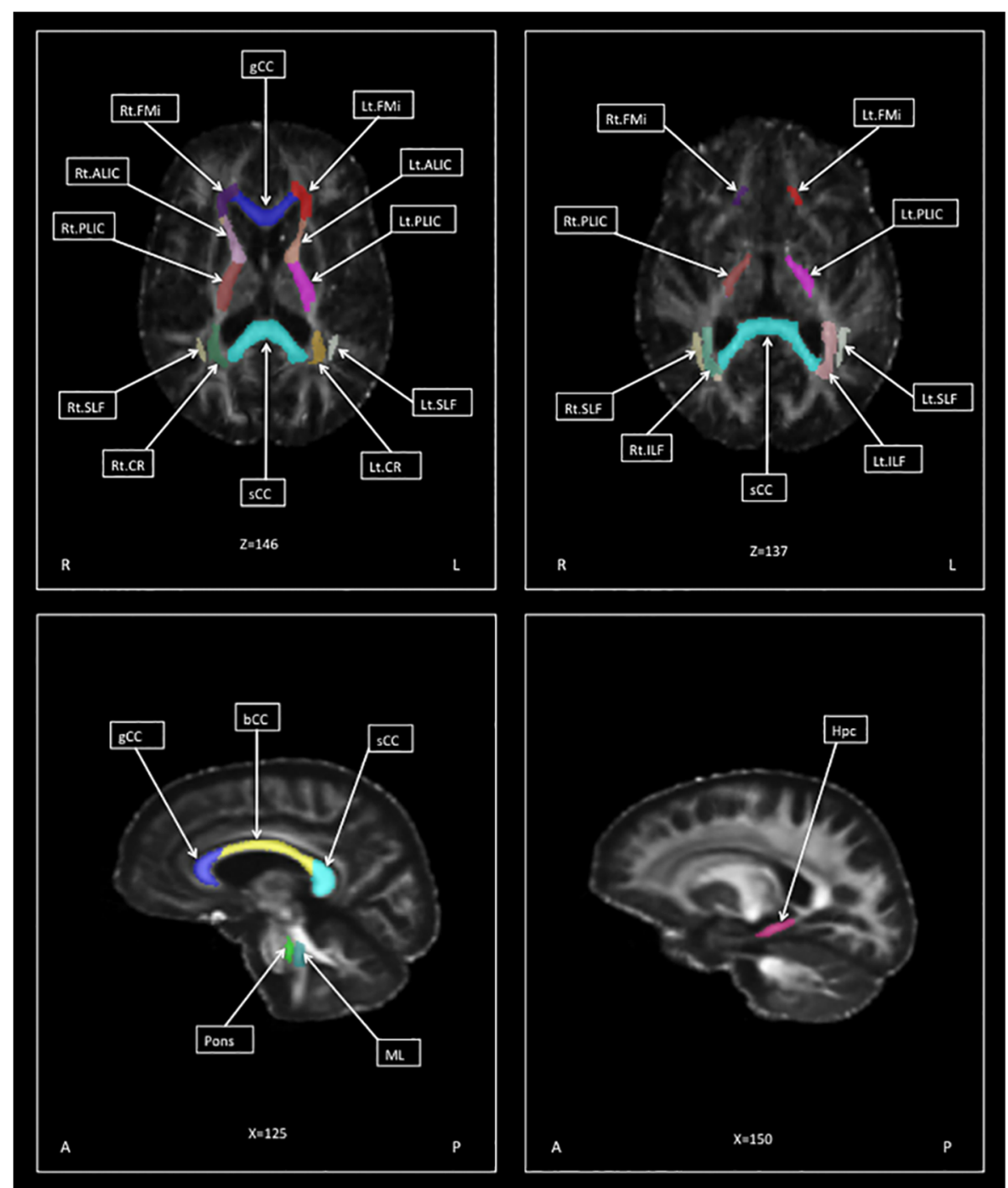

Fig. 1 Regions of interest (ROls) used in the analysis, overlaid on subjects' template

mean FA image and its white matter "skeleton" representing the tracts that are common to all subjects (mean FA skeleton threshold was 0.2), c) projection of individual FA maps onto the image skeleton, d) projection of individual non-FA maps (e.g. MD) using the projections obtained from FA. We performed voxel-wise statistical analysis on the skeleton, with statistical tests as described below.

\section{Region of interest (ROI) analysis}

Using the JHU atlas in subject space, we performed a ROI analysis of the diffusion tensor data in 21 regions; non-midline structures were measured on both sides separately. The regions that were studied are listed in Table 1 . Using ITK-Snap software, placement of ROIs was confirmed by one rater (A.R.A). Mean FA and MD values were extracted for each region as shown in Fig. 1.

\section{Statistical analysis}

Statistical analyses for ROI measurements were performed using Statistical Package for the Social Sciences (SPSS) for Mac (ver. 23.0, SPSS Inc., Chicago, IL, USA). Mean and standard deviation values were calculated for each variable. All data were tested for normality using the Shapiro-Wilk test. For data that were normally distributed, we used the paired-sample t-test. Significant results were set at the level of $p<$ 0.05 . For data that were not normally distributed, group differences were analyzed by Wilcoxon rank test, with a threshold for significance of $\mathrm{p}<0.05$. To 
Table 2 Summary of clinical data

\begin{tabular}{llll}
\hline & At first scan & At second scan & $p$ value \\
\hline Disease duration in months (mean \pm SD) & $27.6 \pm 24$ & $33.0 \pm 24$ & - \\
ALSFRS-R (Mean \pm SD) & $39 \pm 5$ & $38 \pm 4$ & 0.03
\end{tabular}

confirm our results, MANOVA was performed on the significant results correcting for age and gender as covariant.

The selected ROI were used to explore the relationship between FA and MD with disease severity (using ALSRFRS-R) [22] and disease duration from the time of onset of symptoms until the time of the test for each patient over time using a Pearson correlation. The ALSFRS- $\mathrm{R}$ is a scale with 12 domains, with a maximum score of 48 which indicates a lack of symptoms and disability, and a lower score indicates worse disability.

TBSS statistical analysis used a paired t-test design to detect changes between two time-points from the same group of patients. To correct for multiple comparisons across space, we employed permutation testing (5000 permutations) and threshold-free cluster enhancement
(TFCE; [30]). We consider results to be significant at a fully corrected $p<0.05$.

\section{Results}

Subjects

Twenty-three patients with ALS were studied (16 males, 7 females, mean age 59 years, mean ALSFRS-R score of 39 , mean duration at first scan of 27.6 months). These subjects were part of a cohort of 30 ALS patients previously reported [6]. Of the original 30 subjects, 6 declined to have a second scan, usually because of increasing difficulty with mobility and one was deceased before the second scan. Of these 7 patients who did not return for follow-up examination there were 4 males and 3 females. The mean age was 66 years, the mean ALS FRSR score was 36.7 and the mean duration was 16.8 months. Of the

Table 3 Clinical features of ALS patients

\begin{tabular}{|c|c|c|c|c|c|c|c|c|}
\hline Subjects & Age & Gender & Handedness & El Escorial category & Phenotype $^{a}$ & Site of Onset ${ }^{b}$ & Riluzole & Disease duration (months) \\
\hline 1 & 57 & Male & Right & Definite & classic & RLL & Y & 15 \\
\hline 2 & 68 & Male & Right & Definite & classic & LUL & $\mathrm{N}$ & 27 \\
\hline 3 & 74 & Male & Right & Definite & atypical & RUL & $\mathrm{N}$ & 48 \\
\hline 4 & 63 & Female & Left & Definite & classic & LLL & - & 65 \\
\hline 5 & 41 & Male & Right & Definite & classic & RUL & Y & 22 \\
\hline 6 & 65 & Female & Right & Definite & classic & LUL & N & 17 \\
\hline 7 & 51 & Male & Right & Definite & slow progression & LL (Bilateral) & $\mathrm{N}$ & 68 \\
\hline 8 & 47 & Male & Mixed & Definite & flail & LLL & Y & 30 \\
\hline 9 & 57 & Male & Right & Definite & flail & LUL & Y & 28 \\
\hline 10 & 71 & Male & Right & Definite & flail & RLL & Y & 19 \\
\hline 11 & 28 & Female & Right & Definite & UMN & LUL & Y & 13 \\
\hline 12 & 54 & Female & Right & Definite & slow progression & LUL & $\mathrm{N}$ & 2.8 \\
\hline 13 & 66 & Female & Right & Definite & classic & RLL & Y & 6 \\
\hline 14 & 63 & Male & Right & Definite & classic & RUL & $\mathrm{N}$ & 8 \\
\hline 15 & 60 & Female & Right & Definite & classic & LLL & - & 31 \\
\hline 16 & 71 & Male & Right & Definite & classic & RUL & $\mathrm{N}$ & 112 \\
\hline 17 & 52 & Male & Right & Definite & atypical & LUL & Y & 11 \\
\hline 18 & 68 & Male & Right & Definite & slow progression & LLL & $\mathrm{N}$ & 14 \\
\hline 19 & 60 & Male & Right & Definite & classic & Bulbar & $\mathrm{N}$ & 26 \\
\hline 20 & 53 & Male & Right & Definite & UMN & $\mathrm{LL}$ & Y & 27 \\
\hline 21 & 59 & Male & Left & Definite & classic & RLL & N & 11 \\
\hline 22 & 60 & Female & Left & Definite & classic & LLL & $\mathrm{N}$ & 24 \\
\hline 23 & 71 & Male & Right & Definite & classic & Bulbar & $\mathrm{N}$ & 16 \\
\hline
\end{tabular}

${ }^{\mathrm{a}}$ Phenotype as described by Chio et al. 2011 [21]. Those patients with long survival hasve been designated as atypical ${ }^{b}$ RUL: right upper limb, RLL: right lower limb, LUL: left upper limb, LLL: left lower limb, LL: lower limb

' disease duration is taken from the time of onset of symptoms until the time of the first scan 
23 participants, 10 had cognitive impairment (ACE-III score of $<88$ ) and one had abnormal frontal lobe features $(\mathrm{FAB}<12)$.

The clinical details of the participants are summarized in Table 2. The clinical features of the individual ALS subjects are shown in Table 3. The timing of the first scan ranged from 3 to 112 months after the date of onset of ALS (mean 27.6 months). Three patients had long disease duration (patient 4: 65 months, patient 7: 68 months; and patient 16: 112 months). In the interval between the first and second scans there was a small but significant decline in the ALSFRS-R $(p=0.032)$.

\section{TBSS}

Whole brain analysis performed using TBSS showed no significant difference between the first and second scans for ALS subjects. ROI analyses were then used to measure changes in specific brain regions.

\section{ROI studies}

For the motor pathways, there was only a small change in FA between the two scans. In some patients there was a decrease, and in other patients there was an increase in FA. Table 4 shows the mean FA for the first and second scans. There were only small differences between the mean values. Significant increases $(p<$ 0.05 , uncorrected) were observed in the FA along the cortico-spinal tract at the right medial lemniscus (ML), pons, white matter tracts of the right hippocampus and the right anterior limb of internal capsule (ALIC). However, after correcting for multiple comparisons these differences would not be significant. Using MD, there were no significant changes between ROIs over time in any level of the motor pathways (data not shown).

\section{Correlation of FA with ALSFRS-R and disease duration}

We investigated the correlation of FA with ALSFRS-R and disease duration at both time points, as shown in Table 5. At the first scan, the only significant findings were negative correlations the genu of $\mathrm{CC}$, bilateral forceps minor and bilateral ILF ( $p<0.05$, uncorrected). At the time of the second scan, there were no significant correlations. For disease duration, at the first scan, there was a significant negative correlation was in bilateral ALIC $(p<0.05$, uncorrected). At second scan, there were significant negative correlations in the right ALIC and bilateral ILF. However, these findings would not be significant after correcting for multiple comparisons.

Table 4 Comparison of FA at first and second scans

\begin{tabular}{|c|c|c|c|}
\hline $\mathrm{ROI}$ & FA Mean (SD) First scan & FA Mean (SD) Second scan & $p$-value \\
\hline Right FMi & $0.3639(0.03)$ & $0.3647(0.03)$ & 0.586 \\
\hline Left FMi & $0.3605(0.03)$ & $0.3618(0.03)$ & 0.266 \\
\hline $\mathrm{gCC}$ & $0.4887(0.04)$ & $0.4908(0.04)$ & 0.190 \\
\hline bCC & $0.5221(0.04)$ & $0.5230(0.04)$ & 0.689 \\
\hline sCC & $0.5884(0.03)$ & $0.5909(0.03)$ & 0.124 \\
\hline Right CR & $0.4076(0.03)$ & $0.4076(0.03)$ & 0.988 \\
\hline Left CR & $0.4129(0.03)$ & $0.4133(0.03)$ & 0.801 \\
\hline Right PLIC & $0.5517(0.03)$ & $0.5525(0.03)$ & 0.700 \\
\hline Left PLIC & $0.5493(0.03)$ & $0.5520(0.03)$ & 0.220 \\
\hline Right ML & $0.4912(0.02)$ & $0.4988(0.02)$ & 0.029 \\
\hline Left ML & $0.4958(0.02)$ & $0.5007(0.03)$ & 0.163 \\
\hline Pons & $0.3879(0.03)$ & $0.3956(0.03)$ & 0.032 \\
\hline Right ILF & $0.4893(0.03)$ & $0.4895(0.03)$ & 0.306 \\
\hline Left ILF & $0.5053(0.03)$ & $0.5031(0.04)$ & 0.907 \\
\hline Right SLF & $0.4293(0.02)$ & $0.4283(0.03)$ & 0.506 \\
\hline Left SLF & $0.4216(0.03)$ & $0.4218(0.03)$ & 0.898 \\
\hline Right ALIC & $0.4803(0.03)$ & $0.4846(0.03)$ & 0.040 \\
\hline Left ALIC & $0.4732(0.03)$ & $0.4769(0.03)$ & 0.169 \\
\hline Right Hpc & $0.3339(0.02)$ & $0.3402(0.03)$ & 0.038 \\
\hline Left Hpc & $0.3364(0.03)$ & $0.3401(0.02)$ & 0.243 \\
\hline Right Cg & $0.4042(0.03)$ & $0.4046(0.03)$ & 0.832 \\
\hline Left Cg & $0.4171(0.03)$ & $0.4192(0.03)$ & 0.177 \\
\hline
\end{tabular}


Table 5 Correlation of FA with clinical measures

\begin{tabular}{|c|c|c|c|c|c|c|c|c|}
\hline \multirow[t]{2}{*}{$\mathrm{ROI}$} & \multicolumn{2}{|c|}{ ALSFRS-R (Baseline scan) } & \multicolumn{2}{|c|}{ ALSFRS-R (6- month scan) } & \multicolumn{2}{|c|}{ Disease duration (Baseline scan) } & \multicolumn{2}{|c|}{ Disease duration (6- month scan) } \\
\hline & Pearson Correlation & $\begin{array}{l}p \text {-value } \\
\text { (2-tailed) }\end{array}$ & Pearson Correlation & $\begin{array}{l}p \text {-value } \\
\text { (2-tailed) }\end{array}$ & Pearson Correlation & $\begin{array}{l}p \text {-value } \\
\text { (2-tailed) }\end{array}$ & Pearson Correlation & $\begin{array}{l}p \text {-value } \\
\text { (2-tailed) }\end{array}$ \\
\hline Rt.CR & -0.270 & 0.250 & 0.287 & 0.282 & -0.362 & 0.090 & -0.317 & 0.141 \\
\hline Lt.CR & -0.236 & 0.317 & 0.308 & 0.246 & -0.249 & 0.253 & -0.195 & 0.372 \\
\hline Rt.ML & 0.103 & 0.667 & 0.142 & 0.600 & -0.120 & 0.586 & 0.047 & 0.830 \\
\hline Lt.ML & 0.008 & 0.972 & 0.206 & 0.444 & -0.118 & 0.592 & -0.069 & 0.755 \\
\hline Rt.PLIC & -0.178 & 0.453 & -0.048 & 0.860 & 0.069 & 0.753 & -0.179 & 0.414 \\
\hline Lt.PLIC & -0.127 & 0.595 & -0.141 & 0.601 & -0.041 & 0.852 & -0.255 & 0.239 \\
\hline Pons & -0.134 & 0.574 & -0.183 & 0.497 & -0.064 & 0.772 & -0.298 & 0.168 \\
\hline Rt.FMi & -0.649 & 0.002 & -0.173 & 0.521 & -0.354 & 0.098 & -0.378 & 0.076 \\
\hline Lt.FMi & -0.560 & 0.010 & -0.051 & 0.851 & -0.342 & 0.110 & -0.396 & 0.061 \\
\hline gCC & -0.542 & 0.014 & 0.185 & 0.493 & -0.203 & 0.352 & -0.180 & 0.410 \\
\hline bCC & -0.232 & 0.325 & -0.012 & 0.966 & -0.169 & 0.442 & -0.207 & 0.344 \\
\hline $\mathrm{sCC}$ & -0.372 & 0.106 & -0.272 & 0.308 & -0.138 & 0.530 & -0.271 & 0.211 \\
\hline Rt.ILF & -0.594 & 0.006 & -0.266 & 0.319 & -0.404 & 0.056 & -0.431 & 0.040 \\
\hline Lt.ILF & -0.597 & 0.005 & -0.088 & 0.745 & -0.333 & 0.120 & -0.435 & 0.038 \\
\hline Rt.SLF & -0.399 & 0.081 & 0.123 & 0.650 & -0.325 & 0.130 & -0.333 & 0.120 \\
\hline Lt.SLF & -0.389 & 0.090 & 0.271 & 0.311 & -0.245 & 0.261 & -0.315 & 0.143 \\
\hline Rt.Cg & -0.333 & 0.152 & 0.091 & 0.736 & -0.236 & 0.278 & -0.310 & 0.150 \\
\hline Lt.Cg & -0.373 & 0.105 & -0.063 & 0.815 & -0.196 & 0.370 & -0.178 & 0.417 \\
\hline Rt.Hpc & 0.123 & 0.605 & -0.103 & 0.704 & 0.132 & 0.547 & -0.007 & 0.976 \\
\hline Lt.Hpc & -0.223 & 0.346 & -0.217 & 0.419 & -0.056 & 0.799 & -0.276 & 0.202 \\
\hline Rt.ALIC & -0.349 & 0.132 & 0.130 & 0.632 & -0.596 & 0.003 & -0.535 & 0.009 \\
\hline Lt.ALIC & -0.381 & 0.098 & 0.115 & 0.671 & -0.441 & 0.035 & -0.399 & 0.059 \\
\hline
\end{tabular}

Correlation of MD with ALS FRS-R and disease duration The correlations of FA with ALSFRS-R and with disease duration at both time points are shown in Table 6. At the first scan, there were significant positive correlations between MD and ALSFRS-R scores in the left hippocampus, bilateral ALIC, bilateral ILF and SLF $(p<0.05$, uncorrected). Bilateral cingulum, forceps minor and the genu of $\mathrm{CC}$ also showed significant positive correlation ( $\mathrm{p}<0.05$, uncorrected). In the motor pathways, MD at baseline correlated with ALSFRS- $\mathrm{R}$ only in the corona radiata $(\mathrm{p}<0.05$, uncorrected). At the second scan, the only significant correlations were in the right hippocampus $(\mathrm{p}<0.05$, uncorrected). However, these would not be significant after correcting for multiple comparisons.

For MD, at first scan, the only significant correlations with disease duration were in the ALIC, corona radiata, SLF, right ILF and left forceps minor $(p<0.05$, uncorrected). At second scan, MD had significant correlation with disease duration in the ALIC, ILF and SLF. Left forceps minor and right corona radiata showed a positive correlation with disease duration $(\mathrm{p}<0.05$, uncorrected). However, these would not be significant after correction for multiple comparisons.

Correlation between change in FA and change in ALSFRS-R The correlations between the changes in FA with the changes in ALSFRS- $\mathrm{R}$ in different ROIs is shown in Table 7. Statistically significant correlations were observed only in the splenium of the corpus callosum and the right cingulum ( $\mathrm{p}<0.05$, uncorrected), and this would not be significant after correcting for multiple comparisons.

\section{Discussion}

This study was performed to determine the usefulness of DTI of WM tracts in ALS, as a measure of disease progression over a 6-month interval. The ability to measure the progression of ALS using imaging is important for use in prognosis and in clinical trials, and to understand disease pathogenesis [31]. There has been interest in the role of ROI studies in DTI of fiber tracts to evaluate progression of ALS [32, 33] but the results have been variable. A summary of the results of 
Table 6 Correlations of MD with clinical measures

\begin{tabular}{|c|c|c|c|c|c|c|c|c|}
\hline \multirow[t]{2}{*}{$\mathrm{ROI}$} & \multicolumn{2}{|c|}{ ALSFRS-R (Baseline) } & \multicolumn{2}{|l|}{ ALSFRS-R (6- month) } & \multicolumn{2}{|c|}{ Disease duration (Baseline) } & \multicolumn{2}{|c|}{ Disease duration (6- month) } \\
\hline & $\begin{array}{l}\text { Pearson } \\
\text { Correlation }\end{array}$ & $\begin{array}{l}p \text {-value } \\
\text { (2-tailed) }\end{array}$ & Pearson Correlation & $\begin{array}{l}p \text {-value } \\
\text { (2-tailed) }\end{array}$ & Pearson Correlation & $\begin{array}{l}p \text {-value } \\
\text { (2-tailed) }\end{array}$ & $\begin{array}{l}\text { Pearson } \\
\text { Correlation }\end{array}$ & $\begin{array}{l}p \text {-value } \\
\text { (2-tailed) }\end{array}$ \\
\hline Rt.CR & 0.468 & 0.037 & 0.088 & 0.745 & 0.477 & 0.021 & 0.455 & 0.029 \\
\hline Lt.CR & 0.493 & 0.027 & -0.008 & 0.977 & 0.416 & 0.048 & 0.390 & 0.066 \\
\hline Rt.ML & 0.144 & 0.544 & 0.241 & 0.368 & 0.035 & 0.873 & 0.094 & 0.669 \\
\hline Lt.ML & 0.224 & 0.342 & 0.202 & 0.453 & 0.174 & 0.428 & 0.281 & 0.195 \\
\hline Rt.PLIC & -0.301 & .198 & -0.195 & 0.47 & -0.277 & .201 & -.407 & .054 \\
\hline Lt.PLIC & -0.133 & .575 & -0.299 & .837 & -.252 & .247 & -.240 & .270 \\
\hline pons & 0.206 & 0.384 & 0.236 & 0.379 & -0.115 & 0.602 & 0.130 & 0.555 \\
\hline Rt.FMi & 0.530 & 0.016 & 0.212 & 0.430 & 0.351 & 0.101 & 0.344 & 0.109 \\
\hline Lt.FMi & 0.651 & 0.0028 & 0.257 & 0.337 & 0.474 & 0.022 & 0.474 & 0.022 \\
\hline gCC & 0.508 & 0.022 & 0.313 & 0.238 & 0.266 & 0.219 & 0.285 & 0.188 \\
\hline bCC & 0.313 & 0.179 & -0.034 & 0.901 & 0.193 & 0.378 & 0.308 & 0.153 \\
\hline sCC & 0.362 & 0.117 & 0.276 & 0.301 & 0.089 & 0.686 & 0.214 & 0.328 \\
\hline Rt.ILF & 0.652 & 0.002 & 0.358 & 0.173 & 0.445 & 0.033 & 0.520 & 0.011 \\
\hline Lt.ILF & 0.621 & 0.003 & 0.256 & 0.338 & 0.353 & 0.098 & 0.438 & 0.037 \\
\hline Rt.SLF & 0.516 & 0.020 & 0.223 & 0.406 & 0.445 & 0.033 & 0.446 & 0.033 \\
\hline Lt.SLF & 0.623 & 0.003 & 0.059 & 0.829 & 0.497 & 0.016 & 0.530 & 0.009 \\
\hline Rt.Cg & 0.469 & 0.037 & 0.189 & 0.482 & 0.295 & 0.171 & 0.307 & 0.154 \\
\hline Lt.Cg & 0.582 & 0.007 & 0.232 & 0.388 & 0.307 & 0.154 & 0.195 & 0.372 \\
\hline Rt.Hpc & 0.310 & 0.183 & 0.417 & 0.108 & -0.069 & 0.754 & 0.069 & 0.754 \\
\hline Lt.Hpc & 0.478 & 0.033 & 0.553 & 0.026 & -0.146 & 0.507 & -0.001 & 0.995 \\
\hline Rt.ALIC & 0.551 & 0.012 & 0.310 & 0.242 & 0.647 & 0.001 & 0.449 & 0.031 \\
\hline Lt.ALIC & 0.702 & 0.001 & 0.311 & 0.241 & 0.459 & 0.027 & 0.602 & 0.002 \\
\hline
\end{tabular}

other longitudinal studies of ALS is shown in Table 8. Our study has analyzed the results of FA and MD, which were shown to differ between ALS and controls in our previous study [6].

Our study showed that over this time period there was some evidence of clinical progression of ALS patients as seen by a decline in clinical scores of motor function and cognition, but this change was small. Over this time interval there was no significant change in DTI measures using TBSS. ROI analysis of FA and MD revealed some significant changes, however, these would not be significant after correcting for multiple comparisons. There have been inconsistent findings in other serial studies (Table 8), but our work agrees with those who found little change over time.

Using the uncorrected $p$ values, there were some minor changes in the motor pathways over 6 months observation. DTI changes in motor pathways over time would be expected in ALS, which involves degeneration of the motor pathways. Previous studies have shown some evidence of progressive decrease in FA in the CST over time [33, 34]. We found changes only in the right hemisphere, which is consistent with previous work by Steinbach et al. [35]. DTI studies using an ROI method showed a bilateral reduction in FA along the CST [34] while other studies found changes in CST to be confined to the right hemisphere [36]. A recent study from our group has found that handedness has an effect on the site of onset and the spread of pathology [37, 38] and that there is asymmetry of atrophy of the motor cortex in ALS [39]. The greater change in the distal portions of the intracranial CST suggests a pattern of distal degeneration. This has also been reported in previous studies $[40,41]$ and could indicate a dying back of the CST. We found some evidence of progressive changes in the hippocampus. There is known to be atrophy of the hippocampus in ALS [42, 43] and there has been a previous study showing hippocampal abnormality at the advanced stage of ALS [44], but this is the first to show changes over time.

The lack of significant change between scans could be due to the relatively short 6-month interval 
Table 7 Correlation between change in FA and change in ALSFRS-R

\begin{tabular}{lll}
\hline ROI & Pearson correlation & $p$-value (2 tailed) \\
\hline Rt.sCR & -0.009 & 0.969 \\
Lt.SCR & 0.066 & 0.764 \\
Rt.PLIC & -0.140 & 0.523 \\
Lt.PLIC & -0.016 & 0.942 \\
Rt.ML & -0.362 & 0.090 \\
Lt.ML & -0.186 & 0.395 \\
Pons & -0.257 & 0.237 \\
Rt.FMi & -0.150 & 0.496 \\
Lt.FMi & -0.330 & 0.124 \\
gCC & -0.095 & 0.665 \\
bCC & -0.317 & 0.140 \\
sCC & -0.454 & 0.029 \\
Rt.ILF & -0.188 & 0.391 \\
Lt.ILF & -0.364 & 0.088 \\
Rt.SLF & -0.045 & 0.840 \\
Lt.SLF & -0.072 & 0.744 \\
Rt.Cg & -0.534 & 0.009 \\
Lt.Cg & 0.329 & 0.125 \\
Rt.HpC & -0.392 & 0.064 \\
Lt.HpC & -0.376 & 0.077 \\
Rt.ALIC & -0.156 & 0.476 \\
Lt.ALIC & -0.287 & 0.185 \\
\hline & &
\end{tabular}

between scans, as other studies have reported that longer intervals have shown significant changes from baseline [14]. Another reason would be that the patients did not show major change in clinical features, and indeed some of the patients had slow progression. This is a common problem in studies of ALS, where patients with slow progression are often available for inclusion in research projects. Another possibility for the lack of significant change could be the small sample size, and increasing the participant numbers may reveal statistically significant changes. DTI analysis was performed using data that was acquired using optimized parameters for a HARDI analysis, which may affect results slightly.

However, degeneration of upper motor neurons is an early event in ALS $[38,45]$ and white matter tracts may already be substantially damaged by the time of onset of symptoms. The evidence for early damage to upper motor neurons comes from studies showing early changes in cortical excitability [45] and also our previous study that showed that upper motor neuron signs appear before lower motor neuron signs as the disease spreads [38]. It has been estimated that, because of compensation by collateral sprouting, weakness does occur not until many lower motor neurons are lost, and that clinical signs of ALS follow a long subclinical phase [46]. Other studies have shown little change in DTI over time and the authors have suggested that this is because motor tracts are lost early in the disease. A more recent paper also shows that there is little change in DTI over time, although there is progressive loss of grey matter [35, 47-49].

Table 8 Previous serial ROI studies of DTI in ALS

\begin{tabular}{|c|c|c|c|c|c|c|c|}
\hline Study & $\begin{array}{l}\text { Number of } \\
\text { subjects }\end{array}$ & $\begin{array}{l}\text { Mean Age (sd) } \\
\text { at first study }\end{array}$ & $\begin{array}{l}\text { Mean ALS FRS-R (sd) } \\
\text { at first study }\end{array}$ & $\begin{array}{l}\text { Mean ALS FRS R (sd) } \\
\text { at second study }\end{array}$ & $\begin{array}{l}\text { Field } \\
\text { Strength }\end{array}$ & $\begin{array}{l}\text { Duration of } \\
\text { study }\end{array}$ & Significant ROI changes \\
\hline $\begin{array}{l}\text { Kwan et al. } \\
\text { [8] }\end{array}$ & 9 & $57.2(12.6)$ & $40.2(6.3)$ & $34.1(9.8)$ & $3 T$ & $\begin{array}{l}\text { Mean of } \\
1.26 \text { years }\end{array}$ & No change in CR, pons, CST \\
\hline $\begin{array}{l}\text { Steinbach } \\
\text { [49] }\end{array}$ & 16 & $62.1(11.7)$ & $41.0(3.6)$ & $38.2(4.6)$ & $3 \top$ & 3 months & $\begin{array}{l}\text { No change in CST, Increased } \\
\text { connectivity in } \mathrm{Hpc}\end{array}$ \\
\hline $\begin{array}{l}\text { Cardenas- } \\
\text { Blanco [54] }\end{array}$ & 34 & $57.3(9.9)$ & $40.2(4.4)$ & $37.9(5.3)$ & $3 \mathrm{~T}$ & $\begin{array}{l}\text { Mean of } 6 \\
\text { months }\end{array}$ & $\begin{array}{l}\text { No change over time in ALS } \\
\text { group }\end{array}$ \\
\hline Zhang [36] & 17 & $57.3(10)$ & $35.1(7.1)$ & $29.2(9.3)$ & $4 \mathrm{~T}$ & $\begin{array}{l}\text { Mean of } \\
8.1 \text { months }\end{array}$ & $\begin{array}{l}\text { Significant decline in FA in } \mathrm{R} \\
\text { CST }\end{array}$ \\
\hline Keil [52] & 15 & $61.5(10.9)$ & $36.3(9.0)$ & na & $1.5 \mathrm{~T}$ & 6 months & Decline in FA in CST \\
\hline $\begin{array}{l}\text { Nickerson } \\
{[14]}\end{array}$ & 2 & 48 & na & na & $3 T$ & 12 months & Decrease in FA in CST \\
\hline $\begin{array}{l}\text { Mitsumoto } \\
{[17]}\end{array}$ & 30 & $52.6(10.9)$ & $36.4(7.8)$ & na & $1.5 \mathrm{~T}$ & 9.2 months & No change in CST with FA \\
\hline Menke [48] & 27 & $61(11)$ & $35(6)$ & na & $3 \mathrm{~T}$ & $\begin{array}{l}\text { Mean } 16 \\
\text { months }\end{array}$ & No change over time \\
\hline $\begin{array}{l}\text { Bede et al. } \\
\text { [47] }\end{array}$ & 32 & $59.9(9.9)$ & $39.31(6.4)$ & $33.88(7.8)$ & $3 \mathrm{~T}$ & $\begin{array}{l}\text { Mean of } \\
273 \text { days }\end{array}$ & No change in DTI over time \\
\hline
\end{tabular}

na $=$ not available 


\section{Conclusions}

In conclusion, there has been previous evidence of substantial DTI changes of WM in ALS, particularly in the CST [50], frontocallosal connections [51] and limbic pathways [52, 53]. However, our study finds little evidence to support using longitudinal DTI studies to follow patients.

\begin{abstract}
Abbreviations
ACE III: Addenbrookes cognitive examination III; ALS FRSR: ALS functional rating scale revised; ALS: Amyotrophic lateral sclerosis; ANTS: Advance normalization tools software; CST: Corticospinal tract; DTI: Diffusion tensor imaging; FA: Fractional anisotropy; FAB: Frontal assessment battery; FMRIB: Functional MRI of the Brain; FSL: FMRIB software library; GM: Gray matter; HREC: Human research ethics committee; JHU: Johns Hopkins University; MD: Mean diffusivity; MRI: Magnetic resonance imaging; RBWH: Royal Brisbane and Women's Hospital; ROI: Region of interest; SPSS: Statistical Package for the Social Sciences; TBSS: Tract based spatial statistics; WM: White matter
\end{abstract}

\section{Acknowledgements}

We acknowledge the contribution of Ms. Susan Heggie and Ms. Kathryn Thorpe, the research nurses who help with our MND studies.

\section{Funding}

There were no finding sources.

\section{Availability of data and materials}

The MRI data is available from the author on reasonable request.

\section{Authors' contributions}

AA performed the study and analysis and wrote the paper, KP devised and supervised the image processing and contributed to writing the paper, $\mathrm{RH}$ helped recruit and assess the patients, and contributed to writing the paper, MG devised statistical analysis and helped to write the paper, NK contributed image analysis and to writing the paper, PM conceived and supervised the study and contributed to writing the paper. All authors read and approved the final manuscript.

\section{Ethics approval and consent to participate}

The study was approved by the RBWH Human Research Ethics Committee (HREC 2008/98) and all patients provided written informed consent. All activities were conducted in accordance with relevant guidelines.

\section{Consent for publication}

All participants gave written informed consent for participation in the study, which includes dissemination of the results.

\section{Competing interests}

The authors declare that they have no competing interests.

\section{Publisher's Note}

Springer Nature remains neutral with regard to jurisdictional claims in published maps and institutional affiliations.

\section{Author details}

${ }^{1}$ Faculty of Medicine, The University of Queensland, Australia and King Saud University, Brisbane, Australia. ${ }^{2}$ The Australian e-Health Research Centre, CSIRO, Brisbane, Australia. ${ }^{3}$ Department of Neurology, Faculty of Medicine, Royal Brisbane and Women's Hospital and The University of Queensland, Brisbane, Australia. ${ }^{4}$ Centre for Advanced Imaging, The University of Queensland, Brisbane, Australia. ${ }^{5}$ Faculty of Medicine, UQ Centre for Clinical Research, Royal Brisbane and Women's Hospital, The University of Queensland, Herston, QLD 4029, Australia.
Received: 10 April 2018 Accepted: 13 February 2019

Published online: 22 February 2019

\section{References}

1. McCombe PA, Wray NR, Henderson RD. Extra-motor abnormalities in amyotrophic lateral sclerosis: another layer of heterogeneity. Expert Rev Neurother. 2017;17:561-77.

2. Beeldman E, Raaphorst J, Klein Twennaar M, de Visser M, Schmand BA, de Haan RJ. The cognitive profile of ALS: a systematic review and meta-analysis update. J Neurol Neurosurg Psychiatry. 2016;87(6):611-9.

3. Agosta F, Pagani E, Rocca MA, Caputo D, Perini M, Salvi F, Prelle A, Filippi M. Voxel-based morphometry study of brain volumetry and diffusivity in amyotrophic lateral sclerosis patients with mild disability. Hum Brain Mapp. 2007;28(12):1430-8.

4. Canu E, Agosta F, Riva N, Sala S, Prelle A, Caputo D, Perini M, Comi G, Filippi $M$. The topography of brain microstructural damage in amyotrophic lateral sclerosis assessed using diffusion tensor MR imaging. Am J Neuroradiol. 2011;32(7):1307-14.

5. Rose S, Pannek K, Bell C, Baumann F, Hutchinson N, McCombe PA, Henderson RD. Direct evidence of intra- and interhemispheric Corticomotor network degeneration in amyotrophic lateral sclerosis: an automated MRI structural connectivity study. Neuroimage. 2011:59(3):2661-9.

6. Alruwaili AR, Pannek K, Coulthard A, Henderson R, Kurniawan ND, McCombe P. A combined tract-based spatial statistics and voxel-based morphometry study of the first MRI scan after diagnosis of amyotrophic lateral sclerosis with subgroup analysis. J Neuroradiol. 2018:45:41-48.

7. Turner MR, Kiernan MC, Leigh PN, Talbot K. Biomarkers in amyotrophic lateral sclerosis. Lancet Neurol. 2009;8(1):94-109.

8. Kwan JY, Meoded A, Danielian LE, Wu T, Floeter MK. Structural imaging differences and longitudinal changes in primary lateral sclerosis and amyotrophic lateral sclerosis. Neurolmage: Clinical. 2013;2(1):151-60.

9. Carrara G, Carapelli C, Venturi F, Ferraris MM, Lequio L, Chio A, Calvo A, Sirgiovanni S, Cistaro A, Valentini MC. A distinct MR imaging phenotype in amyotrophic lateral sclerosis: correlation between $\mathrm{T} 1$ magnetization transfer contrast hyperintensity along the corticospinal tract and diffusion tensor imaging analysis. AJNR Am J Neuroradiol. 2012;33(4):733-9.

10. Muller HP, Turner MR, Grosskreutz J, Abrahams S, Bede P, Govind V, Prudlo J, Ludolph AC, Filippi M, Kassubek J: A large-scale multicentre cerebral diffusion tensor imaging study in amyotrophic lateral sclerosis. J Neurol Neurosurg Psychiatry. 2016;87:570-9.

11. Pettit $L$, Bastin M, Abrahams S. Executive dysfunction in ALS relates to reduced white matter integrity in the frontal lobes. Amyotroph Lateral Scler. 2012;13:161-2.

12. Sharma KR, Sheriff S, Maudsley A, Govind V. Diffusion tensor imaging of basal ganglia and thalamus in amyotrophic lateral sclerosis. J Neuroimaging. 2013:23:368-74.

13. Hu F, Jin J, Jia R, Xiang L, Qi H, Chen X, Dang J. Spread direction and prognostic factors in limb-onset sporadic amyotrophic lateral sclerosis. Eur Neurol. 2016;75(5-6):244-50.

14. Nickerson JP, Koski CJ, Boyer AC, Burbank HN, Tandan R, Filippi CG. Linear longitudinal decline in fractional anisotropy in patients with amyotrophic lateral sclerosis: preliminary results. Klin Neuroradiol. 2009;19(2):129-34.

15. Sage CA, Van Hecke W, Peeters R, Sijbers J, Robberecht W, Parizel P, Marchal G, Leemans A, Sunaert S. Quantitative diffusion tensor imaging in amyotrophic lateral sclerosis: revisited. Hum Brain Mapp. 2009;30(11): 3657-75.

16. Blain CR, Williams VC, Johnston C, Stanton BR, Ganesalingam J, Jarosz JM, Jones DK, Barker GJ, Williams SC, Leigh NP, et al. A longitudinal study of diffusion tensor MRI in ALS. Amyotroph Lateral Scler. 2007:8(6):348-55.

17. Mitsumoto H, Ulug AM, Pullman SL, Gooch CL, Chan S, Tang MX, Mao X, Hays AP, Floyd AG, Battista $V$, et al. Quantitative objective markers for upper and lower motor neuron dysfunction in ALS. Neurology. 2007;68(17):1402-10.

18. de Albuquerque M, Branco LM, Rezende TJ, de Andrade HM, Nucci A Franca MC Jr. Longitudinal evaluation of cerebral and spinal cord damage in amyotrophic lateral sclerosis. Neurolmage Clinical. 2017;14:269-76.

19. Menke RAL, Proudfoot M, Talbot K, Turner MR. The two-year progression of structural and functional cerebral MRI in amyotrophic lateral sclerosis. Neurolmage Clinical. 2018:17:953-61.

20. Brooks BR, Miller RG, Swash M, Munsat TL. El Escorial revisited: revised criteria for the diagnosis of amyotrophic lateral sclerosis. Amyotroph Lateral Scler Other Motor Neuron Disord. 2000;1 (5):293-9. 
21. Chio A, Calvo A, Moglia C, Mazzini L, Mora G. Phenotypic heterogeneity of amyotrophic lateral sclerosis: a population based study. J Neurol Neurosurg Psychiatry. 2011;82(7):740-6.

22. Cedarbaum JM, Stambler N, Malta E, Fuller C, Hilt D, Thurmond B, Nakanishi A. The ALSFRS-R: a revised ALS functional rating scale that incorporates assessments of respiratory function. BDNF ALS study group (phase III). J Neurol Sci. 1999;169(1-2):13-21.

23. Mioshim E, Dawson K, Mitchell J, Arnokd R, Hodges JR. The Addenbrooke's cognitive examination revised (ACE-R); abrief cognitive test battery for dementia screening. Int J Geriatr Psychiatry. 2006;21:078-85.

24. Hsieh S, Schubert S, Hoon C, Mioshi E, Hodges JR. Validation of the Addenbrooke's cognitive examination III in frontotemporal dementia and Alzheimer's disease. Dement Geriatr Cogn Disord. 2013;36(3-4):242-50.

25. Dubois B, Slachevsky A, Litvan I, Pillon B. The FAB: a frontal assessment battery at bedside. Neurology. 2000;55(11):1621-6.

26. Pannek K, Boyd RN, Fiori S, Guzzetta A, Rose SE. Assessment of the structura brain network reveals altered connectivity in children with unilateral cerebral palsy due to periventricular white matter lesions. Neurolmage: Clinical. 2014;5:84-92.

27. Avants BB, Tustison N, Song G. Advanced normalization tools (ANTS). Insight J. 2009;2:1-35.

28. Wakana S, Jiang H, Nagae-Poetscher LM, Van Zijl PC, Mori S. Fiber tract-based atlas of human white matter anatomy 1. Radiology. 2004; 230(1):77-87.

29. Smith SM, Jenkinson $M$, Johansen-Berg $H$, Rueckert $D$, Nichols TE, Mackay CE, Watkins KE, Ciccarelli O, Cader MZ, Matthews PM, et al. Tract-based spatial statistics: voxelwise analysis of multi-subject diffusion data. Neuroimage. 2006;31(4):1487-505.

30. Smith SM, Nichols TE. Threshold-free cluster enhancement: addressing problems of smoothing, threshold dependence and localisation in cluster inference. Neuroimage. 2009;44(1):83-98.

31. Bowser R, Turner MR, Shefner J. Biomarkers in amyotrophic lateral sclerosis: opportunities and limitations. Nat Rev Neurol. 2011;7(11):631-8.

32. Kassubek J, Muller HP, Del Tredici K, Brettschneider J, Pinkhardt EH, Lule D, Bohm S, Braak H, Ludolph AC. Diffusion tensor imaging analysis of sequential spreading of disease in amyotrophic lateral sclerosis confirms patterns of TDP-43 pathology. Brain. 2014;137(Pt 6):1733-40.

33. Zhang F, Chen G, He M, Dai J, Shang H, Gong Q, Jia Z. Altered white matter microarchitecture in amyotrophic lateral sclerosis: a voxel based metaanalysis of diffusion tensor imaging. Neuroimage Clin. 2018;19:122-29.

34. Jacob S, Finsterbusch J, Weishaupt JH, Khorram-Sefat D, Frahm J, Ehrenreich $H$. Diffusion tensor imaging for long-term follow-up of corticospinal tract degeneration in amyotrophic lateral sclerosis. Neuroradiology. 2003;45(9): 598-600.

35. Steinbach R, Loewe K, Kaufmann J, Machts J, Kollewe K, Petri S, Dengler R, Heinze H-J, Vielhaber S, Schoenfeld MA, et al. Structural hallmarks of amyotrophic lateral sclerosis progression revealed by probabilistic fibe tractography. J Neurol. 2015;262(10):2257-70

36. Zhang Y, Schuff N, Woolley SC, Chiang GC, Boreta L, Laxamana J, Katz JS, Weiner MW. Progression of white matter degeneration in amyotrophic lateral sclerosis: a diffusion tensor imaging study. Amyotroph Lateral Scler. 2011;12(6):421-9.

37. Devine MS, Woodhouse $H_{1}$ McCombe PA, Henderson RD. The relationship between limb dominance, disease lateralization and spread of weakness in amyotrophic lateral sclerosis (ALS). Amyotroph Lateral Scler Frontotemporal Degener. 2013;14(2):150-1.

38. Devine MS, Kiernan MC, Heggie S, McCombe PA, Henderson RD. Study of motor asymmetry in ALS indicates an effect of limb dominance on onset and spread of weakness, and an important role for upper motor neurons. Amyotrophic Lateral Sclerosis and Frontotemporal Degeneration. 2014;15(78):481-7.

39. Devine MS, Pannek K, Coulthard A, McCombe PA, Rose SE, Henderson RD. Exposing asymmetric gray matter vulnerability in amyotrophic lateral sclerosis. Neurolmage Clinical. 2015;7:782-7.

40. Prudlo J, Bissbort C, Glass A, Grossmann A, Hauenstein K, Benecke R, Teipel SJ. White matter pathology in ALS and lower motor neuron ALS variants: a diffusion tensor imaging study using tract-based spatial statistics. J Neurol. 2012:259(9):1848-59.

41. Sheelakumari R, Madhusoodanan M, Radhakrishnan A, Ranjith G, Thomas B. A potential biomarker in amyotrophic lateral sclerosis: can assessment of brain Iron deposition with SWI and corticospinal tract degeneration with DTI help? AJNR Am J Neuroradiol. 2016:37(2):252-8.

42. Abdulla S, Machts J, Kaufmann J, Patrick K, Kollewe K, Dengler R, Heinze H-J, Petri S, Vielhaber S, Nestor PJ. Hippocampal degeneration in patients with amyotrophic lateral sclerosis. Neurobiol Aging. 2014;35(11):2639-45.

43. Christidi F, Karavasilis E, Velonakis G, Ferentinos P, Rentzos M, Kelekis N, Evdokimidis I, Bede P. The clinical an radiological spectrum of hippocampal pathology in amyotrophic lateral sclerosis. Front Neurol 2018;9:532

44. Stoppel CM, Vielhaber S, Eckart C, Machts J, Kaufmann J, Heinze H-J, Kollewe K, Petri S, Dengler R, Hopf J-M. Structural and functional hallmarks of amyotrophic lateral sclerosis progression in motor-and memory-related brain regions. Neurolmage: Clinical. 2014;5:277-90.

45. Menon P, Kiernan MC, Vucic S. Cortical hyperexcitability precedes lower motor neuron dysfunction in ALS. Clin Neurophysiol. 2015;126(4):803-9.

46. Swash $M$, Ingram D. Preclinical and subclinical events in motor neuron disease. J Neurol Neurosurg Psychiatry. 1988;51(2):165-8.

47. Bede P, Hardiman O. Longitudinal structural changes in ALS: a three timepoint imaging study of white and gray matter degeneration. Amyotroph Lateral Scler Frontotemporal Degener. 2018;19(3-4):232-41.

48. Menke RA, Korner S, Filippini N, Douaud G, Knight S, Talbot K, Turner MR. Widespread grey matter pathology dominates the longitudinal cerebral MRI and clinical landscape of amyotrophic lateral sclerosis. Brain. 2014;137(Pt 9): 2546-55.

49. Menke RAL, Proudfoot M, Talbot K, Turner MR. The two year progression of structural and functional cerebral MRI in amyotrophic lateral sclerosis. Neuroimage Clin. 2017:17:953-61.

50. Ellis C, Simmons A, Jones D, Bland J, Dawson J, Horsfield M, Williams S, Leigh P. Diffusion tensor MRI assesses corticospinal tract damage in ALS. Neurology. 1999;53(5):1051

51. Yamauchi H, Fukuyama H, Ouchi Y, Nagahama Y, Kimura J, Asato R, Konishi J. Corpus callosum atrophy in amyotrophic lateral sclerosis. J Neurol Sci. 1995;134(1-2):189-96.

52. Keil C, Prell T, Peschel T, Hartung V, Dengler R, Grosskreutz J. Longitudinal diffusion tensor imaging in amyotrophic lateral sclerosis. BMC Neurosci. 2012;13(1):141.

53. Sarro L, Agosta F, Canu E, Riva N, Prelle A, Copetti M, Riccitelli G, Comi G, Filippi M. Cognitive functions and white matter tract damage in amyotrophic lateral sclerosis: a diffusion tensor tractography study. Am J Neuroradiol. 2011;32(10):1866-72.

54. Cardenas-Blanco A, Machts J, Acosta-Cabronero J, Kaufmann J, Abdulla S, Kollewe K, Petri S, Schreiber S, Heinze H-J, Dengler R, et al. Structural and diffusion imaging versus clinical assessment to monitor amyotrophic lateral sclerosis. Neurolmage: Clinical. 2016;11:408-14.

Ready to submit your research? Choose BMC and benefit from:

- fast, convenient online submission

- thorough peer review by experienced researchers in your field

- rapid publication on acceptance

- support for research data, including large and complex data types

- gold Open Access which fosters wider collaboration and increased citations

- maximum visibility for your research: over $100 \mathrm{M}$ website views per year

At BMC, research is always in progress.

Learn more biomedcentral.com/submission 